\title{
VISUAL OUTCOME AND POST-OPERATIVE COMPLICATIONS OF TRAUMATIC CATARACT
}

\author{
Ishfaq Ahmad Sofi1, Anu Radha Bharti², Satish Kumar Gupta3 ${ }^{3}$ Syed Tariq Qureshi ${ }^{4}$ \\ ${ }^{1}$ Registrar, Department of Ophthalmology, Government Medical College, Srinagar. \\ 2Junior Resident, Department of Ophthalmology, Government Medical College, Jammu. \\ 3 Professor, Department of Ophthalmology, Government Medical College, Jammu. \\ ${ }^{4}$ Professor and HOD, Department of Ophthalmology, Government Medical College, Srinagar.
}

ABSTRACT
BACKGROUND
Ocular trauma is a major cause of visual impairment throughout the world, although little is known about its visual outcome in
developing countries.

AIMS AND OBJECTIVES

To assess the visual outcomes and post-operative complications following the management of traumatic cataracts.

\section{MATERIAL AND METHODS}

This prospective hospital-based study was conducted on 40 patients of traumatic cataract. Patients were managed with lens extraction and intraocular lens implantation. Regular follow-up of patients was done and best corrected visual acuity and postoperative complications were assessed at the end of six months.

\section{RESULTS}

Our study showed that majority ( $50 \%$ ) of patients were in the age group of $<20$ years with male preponderance; 37 cases ( $92.5 \%$ ) were succesfully rehabilitated with IOL implantation as primary or secondary procedure. Out of 40 cases, BCVA of $6 / 18$ - 6/6 was recorded in 28 cases (70\%), 6/36 - 6/24 in 8 cases (20\%) and had BCVA of equal to or less than 6/60 in 10 cases. Most common complications reported were anterior chamber reaction and Posterior Capsular Opacification (PCO).

\section{CONCLUSIONS}

92.5\% patients were safely rehabilitated with cataract extraction and IOL implantation and 70\% had BCVA of 6/18 - 6/6. Posterior capsular opacification and uveitis were the common post-operative complications.

\section{KEYWORDS}

Traumatic Cataract, Visual Outcome, Best Corrected Visual Acuity, Ocular Trauma.

HOW TO CITE THIS ARTICLE: Sofi IA, Bharti AR, Gupta SK, et al. Visual outcome and post-operative complications of traumatic cataract. J. Evolution Med. Dent. Sci. 2016;5(38):2307-2310, DOI: 10.14260/jemds/2016/536

\section{INTRODUCTION}

Ocular trauma is a major cause of monocular blindness and visual impairment throughout the world, although little is known about its epidemiology or associated visual outcome in developing countries.[1] Traumatic cataract is very common sequel of ocular trauma.[2] It may occur when natural lens is damaged either by a blunt or penetrating injury. The methods used to evaluate the visual outcome in eyes managed for traumatic cataracts and senile cataracts are similar. ${ }^{[3]}$ but the damage to other ocular tissues due to trauma may compromise the visual gain in eyes operated on for traumatic cataracts. Post-operative inflammation is a common complication following traumatic cataracts, hampering visual outcome. $[4,5,6,7,8]$ Other complications leading to decreased post-operative vision are corneal scar, uveitis, secondary glaucoma, pupillary capture, posterior capsular opacification and retinal scar.[4] The aim of this study was to assess the visual outcomes and post-operative complications following the management of traumatic cataracts.

Financial or Other, Competing Interest: None.

Submission 24-03-2016, Peer Review 21-04-2016,

Acceptance 28-04-2016, Published 11-05-2016.

Corresponding Author:

Dr. Ishfaq Ahmad Sofi,

Room No. 402,

Doctor's Hostel,

Opp. Casuality Block,

SMHS Hospital, Karan Nagar

Srinagar-190010, J\& K

E-mail:drsofiishfaq@gmail.com

DOI: $10.14260 /$ jemds $/ 2016 / 536$

\section{AIMS AND OBJECTIVES}

The aim of this study was to assess the visual outcomes and post-operative complications following the management of traumatic cataracts.

\section{MATERIAL AND METHODS}

This prospective study was carried out in the upgraded Department of Ophthalmology Government Medical College, Jammu, from $1^{\text {st }}$ July 2011 to $31^{\text {st }}$ October 2012. A comprehensive proforma was designed for this study. The study was conducted on patients of traumatic cataract as a result of ocular injury from blunt or penetrating trauma admitted in the department. Patients who gave consent and were cooperative and willing for the surgery were included. Personal information of all the patients was recorded. After admission to the hospital, detailed history was taken with particular reference to age, sex and mode of injury, causes and activity at the time of injury. Preoperative assessment included: Best Corrected Visual Acuity (BCVA) by Snellen testtype, extraocular movements, fixation preferences, pupillary reflexes, slit lamp biomicroscopy of the anterior segment, applanation tonometry, dilated refraction, fundus examination with indirect ophthalmoscope, keratometry (Opposite normal eye was used in case of corneal surface irregularities), intraocular lens power calculation and B-scan was done. Other relevant examinations and routine investigations were also done as well before surgery. Corneal laceration more than 10 $\mathrm{mm}$, injuries like iridodialysis, zonular dehiscence, vitreous 
haemorrhage, retinal detachment, cases with age less than two years were excluded from the study.

All cases were subjected to surgery under local or general anaesthesia. The standard surgical procedure performed was SICS with posterior chamber IOL implantation, primary lens aspiration at the time of wound repair with primary or secondary IOL implantation. These surgical procedure was combined with other surgical procedures depending upon the need in individual cases. Post-operatively, all patients were treated with topical steroids along with topical antibiotics and non-steroidal anti-inflammatory drugs. Steroids were gradually tapered over next six weeks to two months. Patients were discharged with topical antibiotics, steroids and topical cycloplegics. Patients were called for regular follow-up after three days, then once a week for next six weeks, monthly for next three months and thereafter every three months. On follow-up visual acuity, IOP recording, detailed slit lamp biomicroscopy to rule out any uveitis, intraocular lens decentration, synechiae, pupillary capture and posterior capsular opacification were done. Posterior segment evaluation was done with indirect ophthalmoscopy.

This study was in accordance with the ethical standards of Declaration of Helsinki and was approved by the Ethical Committee of the Institution. A written informed consent was taken from all the participants. Forty cases that were admitted in our institution were studied over a period of one and a half year from July 2011 to October 2012.

\section{RESULTS}

In this study, $50 \%$ cases were found in the age group of 5-20 years followed by $32.5 \%$ in age group $21-40$ years. The male:female ratio is $3: 1$.

Majority of patients $(62.5 \%)$ had traumatic cataract due to penetrating trauma and $37.5 \%$ due to blunt trauma. Causative agents of trauma include wooden particles like stick, thorn and bow arrow in 24 cases (60\%), metallic agents like iron rod, wire, compass in 4 cases (10\%), stone in 2 cases (5\%) and with glass piece in $4(10 \%)$ cases.

The morphology of traumatic cataract was total in 27 cases $(67.5 \%)$, soft cataract with ruptured anterior capsule in 6 cases $(24 \%)$ and membranous and rosette cataract in 2 cases (8\%) each. Table 1 shows Best Corrected Visual Acuity (BCVA) at the time of presentation.

The interval between trauma and surgery was less than three months in 24 cases (60\%), 4-6 months in 7 cases (17.5\%), 7-12 months in 3 cases (7.5\%), 13-18 months in 2 cases (5\%) and more than 18 months in 4 cases (10\%).

Out of 40 cases, 37 cases $(92.5 \%)$ were succesfully rehabilitated with IOL implantation as primary or secondary procedure; 30 cases underwent cataract extraction (SICS) with PCIOL; 9 cases presented with anterior capsular defect with presence of lens matter in anterior chamber. Among these, 4 cases underwent primary lens aspiration with primary IOL implantation and 3 cases had undergone only lens aspiration at the primary sitting with subsequent secondary IOL implantation at a later date. Three cases (7.5\%) remained aphakic. Figure 1 summarises type of IOL implantation in the study patients.

A number of intraoperative and postoperative (early and late) complications were noted. Vitreous loss was seen in 3 $(7.5 \%)$ cases and hyphema in $2(5 \%)$ cases. Postoperative complications noted are shown in Table 2.
In patients with significant posterior capsule opacification, Nd-YAG laser capsulotomy was done in 7 (17.5\%) and membranectomy in $1(2.5 \%)$.

Final BCVA was assessed at the end of 6 months. Out of 40 cases, BCVA of $6 / 18-6 / 6$ was recorded in 28 cases $(70 \%)$. BCVA of $6 / 36-6 / 24$ was seen in 8 cases $(20 \%) ; 10$ cases had BCVA equal to or less than $6 / 60$ as shown in Table 3.

\begin{tabular}{|c|c|c|}
\hline Initial VA & $\begin{array}{c}\text { Number } \\
\text { of Cases }\end{array}$ & Percentage \\
\hline$>6 / 60$ & 1 & 2.5 \\
\hline $1 / 60-6 / 60$ & 10 & 25 \\
\hline $\mathrm{CF}-1 / 2 \mathrm{mt}$ & 2 & 5 \\
\hline $\mathrm{HM}$ & 4 & 10 \\
\hline $\mathrm{PL} / \mathrm{PR}$ & 23 & 57.5 \\
\hline Total & 40 & 100 \\
\hline \multicolumn{2}{|c|}{ Table 1: Best Corrected Visual Acuity (BCVA) } \\
at the Time of Presentation \\
\hline
\end{tabular}

\begin{tabular}{|c|c|c|}
\hline $\begin{array}{l}\text { Post-operative } \\
\text { Complications }\end{array}$ & $\begin{array}{l}\text { Number of } \\
\text { Patients }\end{array}$ & Percentage \\
\hline Increased IOP & 3 & 7.5 \\
\hline Uveitis & 11 & 27.5 \\
\hline Pupillary capture & 2 & 5 \\
\hline PCO & 12 & 30 \\
\hline Macular oedema & 3 & 7.5 \\
\hline Corneal oedema & 4 & 10 \\
\hline Hyphema & 2 & 5 \\
\hline \multicolumn{3}{|c|}{ Table 2: Post-operative Complications } \\
\hline
\end{tabular}

\begin{tabular}{|c|c|c|c|}
\hline \multicolumn{4}{|c|}{ BCVA at 6 Months } \\
\hline \multicolumn{2}{|c|}{ Best Corrected Visual Acuity (BCVA) } & \multirow{2}{*}{ Total } \\
6/6 to 6/18 & $\begin{array}{c}\text { 6/24 to 6/60 } \\
\text { n (\%) }\end{array}$ & $\begin{array}{c}<6 / 60 \\
\text { n (\%) }\end{array}$ & (\%) \\
\hline $28(70 \%)$ & $11(27 \%)$ & $1(2.5 \%)$ & $40(100 \%)$ \\
\hline \multicolumn{3}{|c|}{ Table 3: Final Best Corrected Visual Acuity at Six } \\
Months
\end{tabular}

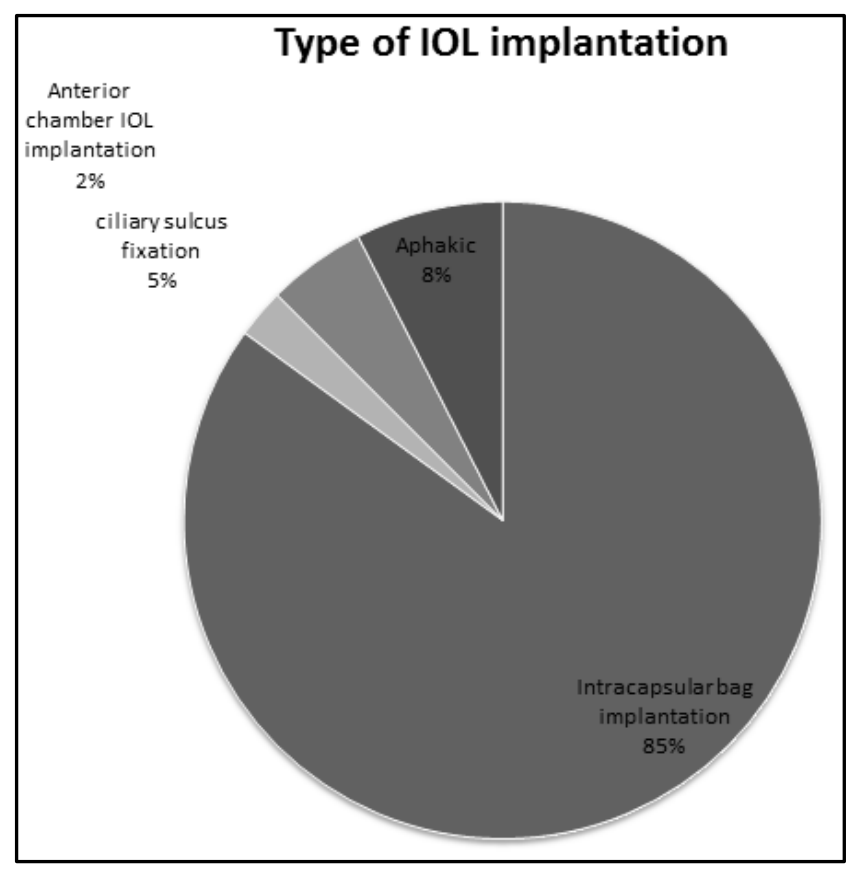

Fig. 1: Pie Diagram Showing Type of IOL Implantation 


\section{DISCUSSION}

The present study brought within its preview 40 patients of traumatic cataract admitted in Department of Ophthalmology, Govt. Medical College, Jammu, from July 2011 to October 2012. Injury to the eye represents a major threat to vision and this may happen to any individual at any age in any work place. Ocular trauma often leads to traumatic cataract along with damage to other ocular structures. Traumatic cataract was managed with lens extraction and intraocular lens implantation. Regular follow-up of patients was done and visual outcome was assessed at the end of six months. In the present study demographic, aetiological factors, type of trauma, pre-operative visual acuity, type of surgery, postoperative best corrected visual acuity and complications were assessed and analysed.

Our study showed that majority ( $50 \%$ ) of patients were in the age group of $<20$ years followed by $32.5 \%$ in the age group of 21-40 years, almost similar to the results of some other studies. ${ }^{[9,10]}$ while Panda A et al have reported maximum patients $(31.25 \%)$ in the age group of $25-34$ years.[11] In the present study, we found male preponderance of $3: 1$, as shown by most of the other studies. ${ }^{[4,9,11-13]}$ In our study blunt trauma accounts for traumatic cataract in $37.5 \%$ and penetrating trauma in $62.5 \%$ of cases. Our results were consistent with the results obtained by Memon MN et al that penetrating trauma accounts for traumatic cataract in $68.3 \% .{ }^{[13]}$ Synder A et al observed penetrating trauma in $78.6 \%$ of cases.[12] and Staffieri SE et al observed $88 \%$ cases of traumatic cataract due to penetrating trauma.[14] while Gogate $\mathrm{P}$ et al observed traumatic cataract in $48.8 \%$ of cases due to blunt trauma and $39 \%$ of cases due to sharp trauma.[15]

In our study wooden material like stick, thorn was the major cause of traumatic cataract which matches closely with study of Memon MN et al[13] and Shah MA.[16] In our study, $67.5 \%$ had total cataract which matches with study of Panda A et al, which had $74 \%$ total cataract.[11] In our study soft cataract was noticed in $22.5 \%$, which is consistent with the study of Zaman M et al, which had soft cataract with ruptured anterior capsule in $25.97 \%$ of cases. ${ }^{[9]}$ Shah $\mathrm{M}$ et al in their study showed $59.9 \%$ patients had white soft cataract with ruptured anterior capsule followed by $26.6 \%$ had total cataract.[16] In our study more than half of patients had pretreatment best corrected visual acuity of light perception only, which is consistent with study of Ahmed $\mathrm{N}$ et al[10] where half of patients had visual acuity of hand movement and with study of Kumar S et al[17] where maximum patient had visual acuity of light perception only.

In the present study, time interval between trauma and cataract surgery ranges from same day to 10 years. Maximum patients $(60 \%)$ presented to the hospital and underwent cataract surgery within 3 months, $17.5 \%$ patients within $4-6$ months, $10 \%$ patients were operated upon after 18 months, 7.5\% patients within 7-12 months followed by $5 \%$ within $13-$ 18 months. One $(2.5 \%)$ patient was operated for traumatic cataract 10 years after trauma, while Eckstein $\mathrm{M}$ et al in their study showed time interval between injury and cataract surgery ranged from 1-60 weeks with mean interval was 10.4 weeks.[18] In our study $92.5 \%$ patients were safely rehabilitated with IOL implantation which is consistent with the study of Panda A et al, as they put IOL in $89.2 \%$ of patients.[11] and Gogate P et al in $90.2 \%$ of patients.[15] Most common complications reported in our study were anterior chamber reaction and PCO, which is consistent with study of Memon MN et al[13], Zaman M et al[9], Synder et al[12], Loncar VL et al[19], Kumar $S$ et al.[17] Patients with uveitis were given topical corticosteroids (Prednisolone acetate 1\% eye drops) and cycloplegics and they responded within six weeks. One (2.5\%) patient with PCIOL in our study had intractable raised IOP; peripheral laser iridotomy was done and later on IOP remained normal. In the present study $30 \%$ had clinically significant PCO, Nd-YAG laser capsulotomy was performed in $17.5 \%$ of cases and one $(2.5 \%)$ patient had very thick PCO which was resistant for Laser; in this patient surgical membranectomy was done at an interval of 4 months after surgery which matches with study of Eckstein $M$ et al[18] in which Nd-YAG laser capsulotomy was performed in $63.46 \%$, more than one laser session required in $11.53 \%$ and surgical membranectomy was done in $17.3 \%$. This study revealed that satisfactory visual outcome in majority of patients with traumatic cataract can be safely achieved after cataract removal and IOL implantation and common causes of decreased vision were corneal scar, Posterior Capsular Opacification (PCO) and uveitis as was shown by other studies.[10,11,13]

\section{SUMMARY AND CONCLUSION}

Traumatic cataract resulting from ocular trauma is a common cause of ocular morbidity, especially in young population. Most of the injury occur by wooden particles like stick. Most injury occur while playing or doing domestic/agricultural work; $92.5 \%$ patients were safely rehabilitated with cataract extraction and IOL implantation and $70 \%$ had BCVA of $6 / 18$ $6 / 6$. Posterior capsular opacification and uveitis were the common post-operative complications.

\section{REFERENCES}

1. Khatry SK, Lewis AE, Schein OD, et al. The epidemiology of ocular trauma in rural Nepal. $\mathrm{Br} J$ Ophthalmol 2004;88(4):456-60.

2. Thakker MM, Ray S. Vision limiting complications in open globe injuries. Can J Ophthalmol 2006;41(1):86-92.

3. Kuhn F, Morris R, Witherspoon CD, etal. The birmingham eye trauma terminology system (BETT). J Fr Ophtalmol 2004;27(2):206-10.

4. Bekibele CO, Fasina O. Visual outcome of traumatic cataract surgery in Ibadan, Nigeria. Niger J Clin Pract 2008;11(4):372-5.

5. Koenig SB, Ruttum MS, Lewandowski MF, et al. Pseudophakia for traumatic cataracts in children. Ophthalmology 1993;100(8):1218-24.

6. Mohammadpour M, Jafarinasab MR, Javadi MA. Outcomes of acute postoperative inflammation after cataract surgery. Eur J Ophthalmol 2007;17(1):20-8.

7. Hemo Y, BenEzra D. Traumatic cataracts in young children. Correction of aphakia by intraocular lens implantation. Ophthalmic Paediatr Genet 1987;8(3):203-7.

8. Awner S, Buckley EG, DeVaro JM, et al. Unilateral pseudophakia in children under 4 years. J Pediatr Ophthalmol Strabismus 1996;33(4):230-6.

9. Zaman M, Iqbal S, Sanaullah, et al. Frequency and visual outcome of traumatic cataract. J Postgrad Med Inst 2006;20(4):330-4. 
10. Ahmed N, Aziz T, Akram S. Visual outcome after primary IOL implantation for traumatic cataract. Pak J Ophthalmol 2011;27(3):152-4.

11. Panda A, Kumar S, Das H, et al. Striving for the perfect surgery in traumatic cataract following penetrating trauma in tertiary care hospital in eastern Nepal. J Nepal Med Assoc 2007;46(167):119-25.

12. Synder A, Kobielska D, Omulecki W. Intraocular lens implantation in traumatic cataract. Klin Oczna 1999;101(5):343-6.

13. Memon MN, Narsani AK, Nizamani NB. Visual outcome of unilateral traumatic cataract. J Coll Physicians Surg Pak 2012;22(8):497-500.

14. Staffieri SE, Ruddle JB, Mackey DA. Rock, Paper and scissors? Traumatic pediatric cataract in Victoria 19922006. Clin Experiment Ophthalmol 2010;38(3):237-41.
15. Gogate $P$, Sahasrabudhe $M$, Shah $M$, et al. Causes, epidemiology, and long term outcome of traumatic cataracts in children in rural India. Indian J Ophthalmol 2012;60(5):481-6.

16. Shah MA, Shah SM, Shah SB, et al. Morphology of traumatic cataract: does it play role in final visual outcome. BMJ Open 2011;1(1):e000060. doi: 10.1136./ bmjopen-2011-000060.

17. Kumar S, Panda A, Badhu BP, et al. Safety of primary intraocular lens insertion in unilateral childhood traumatic cataract. J Nepal Med Assoc 2008;47(172):179-85.

18. Eckstein M, Vijayalakshmi P, Killedar M, et al. Use of intraocular lenses in children with traumatic cataract in south India. Br J Ophthalmol 1998;82(8):911-5.

19. Loncar VL, Petric I. Surgery treatment, clinical outcomes, complications of traumatic cataract: retrospective study. Croat Med J 2004;45(3): 310-3. 